\title{
A simple dressing for hypospadias surgery in children
}

\author{
Roberto Méndez-Gallart, MD; María García-Palacios, MD; Pablo Rodríguez-Barca, MD; \\ Elina Estévez-Martínez, MD; Ana Lema Carril, MD; Adolfo Bautista-Casasnovas, MD
}

Department of Pediatric Surgery \& Urology, University Hospital of Santiago, Santiago de Compostela, Spain

Cite as: Can Urol Assoc J 2017;11 (1-2):E58-9. ttp://dx.doi.org/10.5489/cuaj.3930

Published online January 12, 2107

\section{Abstract}

One of the most controversial aspects of hypospadias surgery is the election of an appropriate wound dressing. In fact, there may be as many different types of dressing as there are types of surgical repair. Here, we describe a new, simple method for hypospadias dressing in children that minimizes painful removal.

\section{Method}

One of the most controversial aspects of modern hypospadias surgery is the election of an appropriate wound dressing. ${ }^{1}$ Multiple dressings after hypospadias surgery have been previously reported. ${ }^{2}$ Dressing prevents postoperative edema and hematoma formation, maintaining the phallus in an upright position. Most dressings are bulky, hard to apply or remove, and may fall off in an active child. ${ }^{3}$ Commonly used dressings are adherent to the surgical wound, making removal more likely to be painful, especially in young children. ${ }^{4}$ Diverse types of materials have been used for this purpose, including petrolatum-based gauze, silastic foam, elastic bandage, glove finger, Tegaderm ${ }^{\top M}$, Opsite ${ }^{\circledR}$, CaviCare $^{\circledR}$, Granuflex ${ }^{\circledR}$, Dermolite ${ }^{\mathrm{TM}}$, and Coban ${ }^{\mathrm{TM}}$ bandage. ${ }^{3,4}$ All the above-mentioned materials have their own set of advantages and disadvantages. Under these conditions, the use of a self-adherent, soft, silicone-foam dressing that minimizes painful removal is really appropriate for hypospadias surgery. ${ }^{5}$

The Mepilex ${ }^{\circledR}$ Border foam sheet is cut according to the penile length and circumference. The lower border of dressing is split in three flaps for self-adherence to pubic and scrotal area (Fig. 1). The foam dressing need to be rolled into a cylindrical shape, wrapping round the penis and closed on the dorsal aspect with adhesive lateral border (Fig. 2). The top of the dressing must be left open to allow the urinary catheter to come through and to see the colour of the glans during postoperative period. No secondary dressings are necessary. The application of this type of dressing is very simple, with no need for previous skills and without increasing the operation time.

The dressing is removed after 5-10 days, depending on the urethroplasty procedure performed. The dressing, being non-adherent in the wound area, is easily peeled off with no need of analgesics and minimal discomfort (Fig. 3).

\section{Conclusion}

Self-adherent, soft, silicone-foam dressing (Mepilex ${ }^{\circledR}$ Border) is really accurate for hypospadias surgery in children. It can be easily removed, avoiding harm to the child.

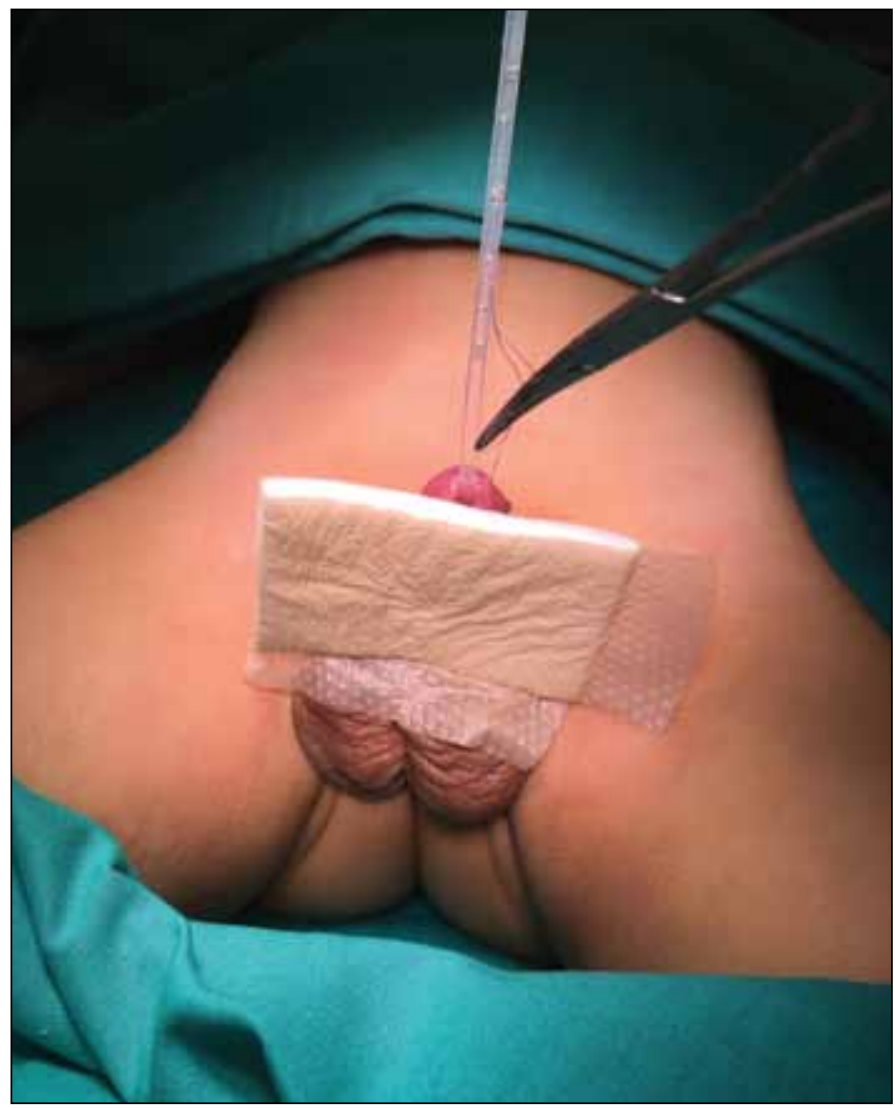

Fig. 1. Mepilex ${ }^{\circledR}$ Border adapted to the penis size after surgery. 


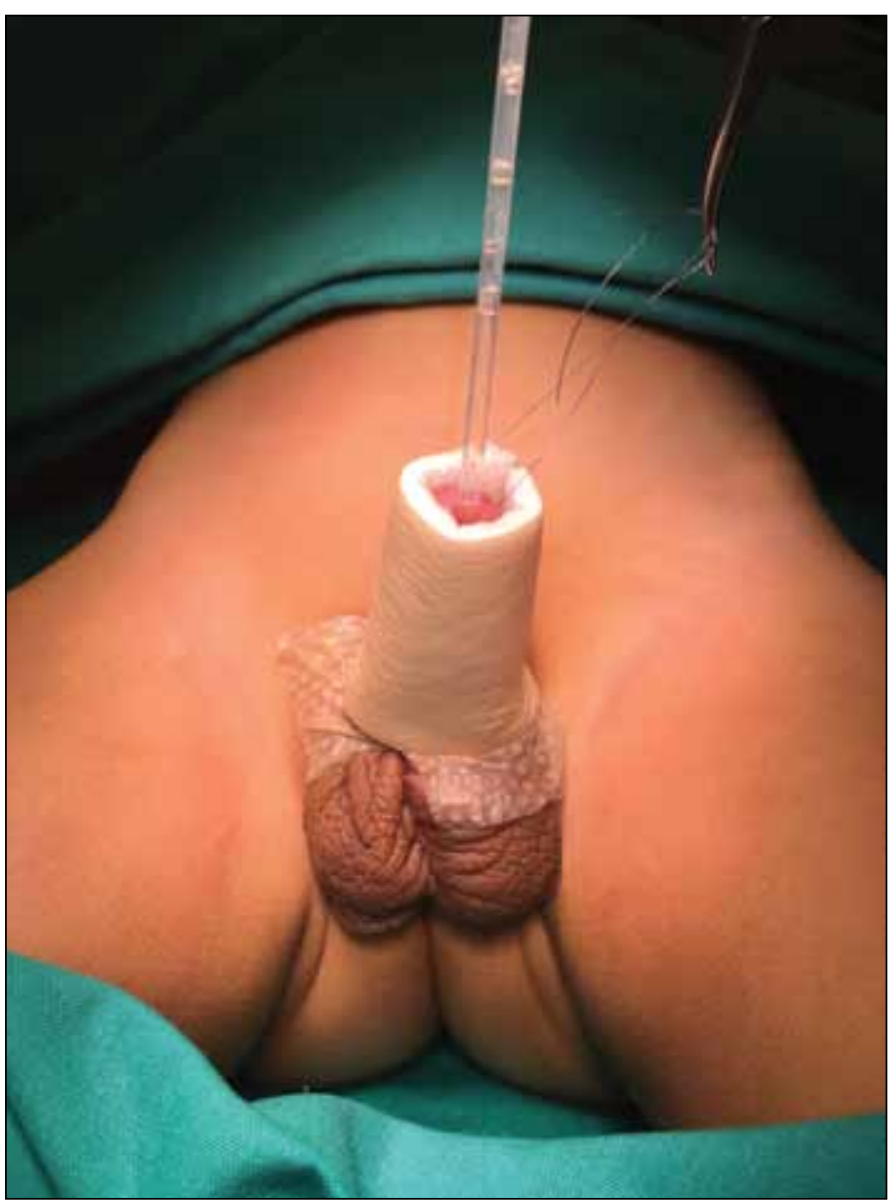

Fig 2. Silicone border foam dressing rolled into a cylindrical shape around the penis.

Competing interests: The authors report no competing personal or financial interests.

This paper has been peer-reviewed.

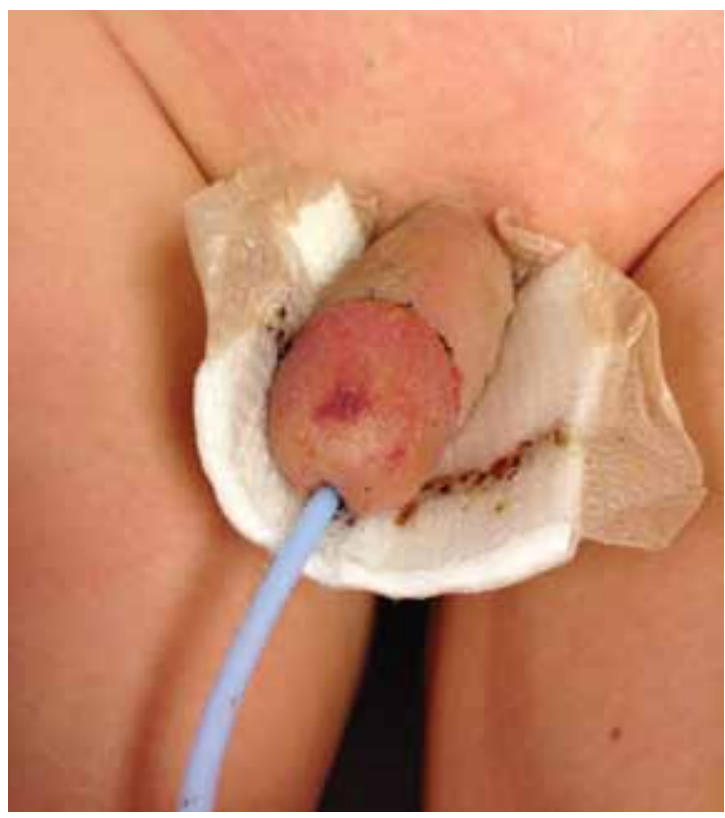

Fig 3. Painless, simple removal of the dressing.

\section{References}

1. McLorie $G$, Joyner B, Herz D, et al. A prospective, randomized clinical trial to evaluate methods of postoperative care of hypospadias. J Urol 2001;165:1669-72. https://doi.org/10.1016/S00225347(05)66388-4

2. Hadidi A. Dressing vs. no dressing. In: Hadidi AT, Azmy AF eds. Hypospadias surgery. Springer, Berlin, 2004:271-72

3. Van Savage JG, Palanca LG, Slaughenhoupt BL. A prospective, randomized trial of dressing vs. no dressings for hypospadias repair. J Urol 2000;164:981-3. https://doi.org/10.1016/S0022-5347(05)67231-X

4. Narci A, Embleton DB, Boyaci EÖ, et al. A practical offer for hypospadias dressing: Allevyn. Afr J Paediatr Surg 2011;8:272-4. https://doi.org/10.4103/0189-6725.91658

5. De Sy WA, Oosterlinck W. Silicone foam elastomer: A significant improvement in postoperative penile dressing. J Urol 1982;128:39-4.

Correspondence: Dr. Roberto Méndez-Gallart, Department of Pediatric Surgery \& Urology, University Hospital of Santiago, Santiago de Compostela, Spain; roberto.mendez.gallar†@sergas.es 